\title{
Surgical treatment of a solitary pulmonary metastasis from eyelid sebaceous carcinoma: report of a case
}

\author{
Kaoru Kaseda ${ }^{1}$, Takashi Ohtsuka1* Yuichiro Hayashi², Katsura Emoto², Keisuke Asakura', Ikuo Kamiyama', \\ Taichiro Goto ${ }^{1}$ and Mitsutomo Kohno ${ }^{1}$
}

\begin{abstract}
Background: Ocular sebaceous carcinoma is an uncommon, aggressive ocular neoplasm with potential for regional and distant metastasis.

Case presentation: A 77-year-old woman was found to have a solitary pulmonary lesion 6 years after the initial treatment of sebaceous carcinoma of the eyelid. Video-assisted lung wedge resection of an undetermined pulmonary nodule was carried out successfully. Microscopically, the tumor showed foamy cytoplasm and atypical nuclei, consistent with metastasis of eyelid sebaceous carcinoma.
\end{abstract}

Conclusion: This is the first case report of resected solitary pulmonary metastasis of eyelid sebaceous carcinoma. Pulmonary resection is a good option for the treatment and diagnosis of metastatic eyelid sebaceous carcinoma.

Keywords: Sebaceous carcinoma, Lung metastasis, Solitary metastasis

\section{Background}

Sebaceous carcinoma of the eyelid is a relatively rare malignant tumor, and accounts for less than $1 \%$ of all eyelid tumors [1]. As well as being a rare tumor, sebaceous carcinoma can mimic other benign inflammatory and malignant processes, thus errors or delays in diagnosis are not unusual [2-5]. Although local management strategies for this tumor have previously been described [6-10], very few reports have focused on the patterns of metastasis of this tumor and the treatment strategies for such metastases $[7,8]$. Here, we report a case of solitary lung metastasis of eyelid sebaceous carcinoma, and discuss the clinical implication of surgery for a solitary pulmonary metastasis from sebaceous carcinoma.

\section{Case presentation}

A 77-year-old woman underwent left upper lid resection in April 2006 for sebaceous carcinoma of the eyelid. The surgical margin was negative for cancer cells. In January

\footnotetext{
* Correspondence: t-oh@remus.dti.ne.jp

'Department of Surgery, Section of General Thoracic Surgery, Keio University, 35 Shinanomachi, Shinjuku-ku, Tokyo 160-8582, Japan

Full list of author information is available at the end of the article
}

2008, she had developed a recurrence in the left upper eyelid, and underwent radiotherapy with a total dose of 57.6 Gy of proton beam therapy followed by orbital exenteration of the left eye [11,12]. In July 2012, positron emission tomography-computed tomography (PET-CT) revealed a solitary pulmonary nodule $0.5 \mathrm{~cm}$ in size in the right upper lobe of the patient's lung, which had increased to $1.1 \mathrm{~cm}$ by September 2013 (Figure 1A). PET-CT revealed a focus of increased uptake in that nodule, with a standardized uptake value of 3.7 (Figure 1B). There was no evidence of other metastatic disease on PET-CT scans. In September 2013, the patient underwent video-assisted thoracoscopic wedge resection of the pulmonary nodule. Frozen sections using oil red $\mathrm{O}$ stain revealed accentuation of lipid and presences of foamy cytoplasm in tumor cells, which was positive for lipid staining (Figure 2). Permanent histology demonstrated tumor cells with foamy cytoplasm and atypical nuclei, accompanying numerous lipid globules within the cytoplasm (Figure 3), consistent with metastasis of eyelid sebaceous carcinoma. At the last follow-up, 7 months after resection, there was no loco-regional recurrence or distant metastasis of the tumor after surgery. 

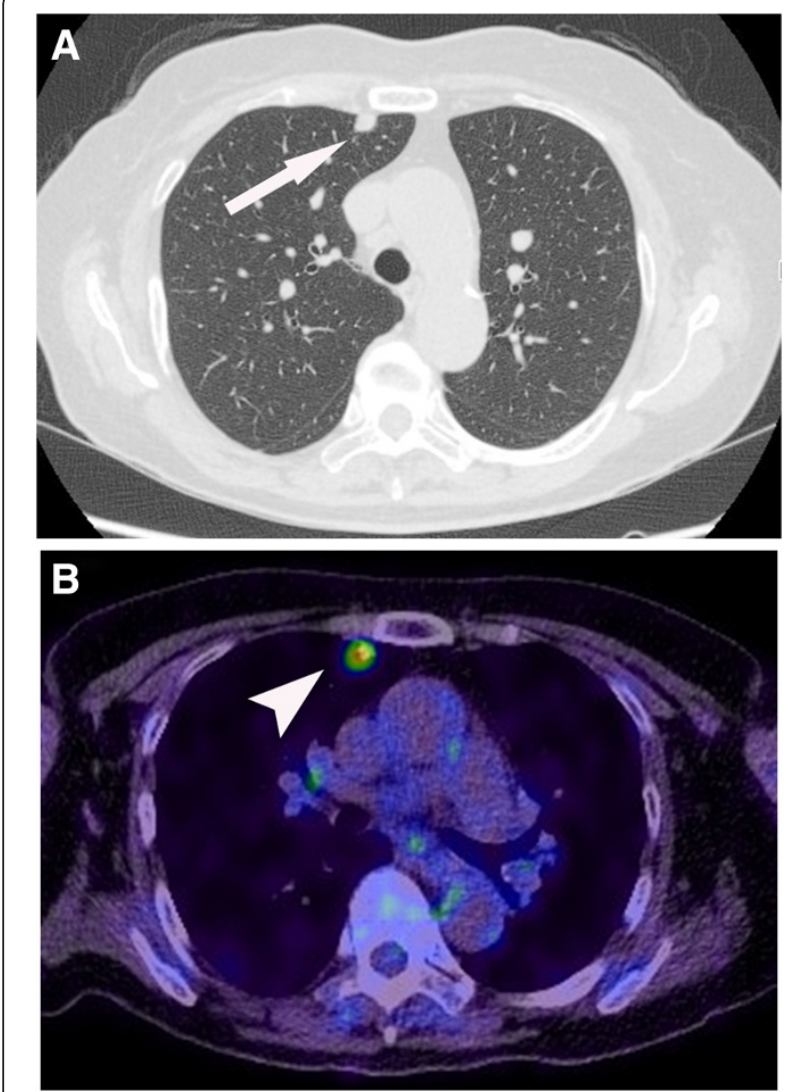

Figure 1 Computed tomography (CT) and positron emission tomography of the tumors. (A) Chest $C T$ showed a $1.1 \mathrm{~cm}$ nodule in the anterior segment of the right upper lobe (arrow). (B) PET-CT showed fluorodeoxyglucose accumulation with a Standardized uptake value (SUV) of 3.7 (arrowhead).

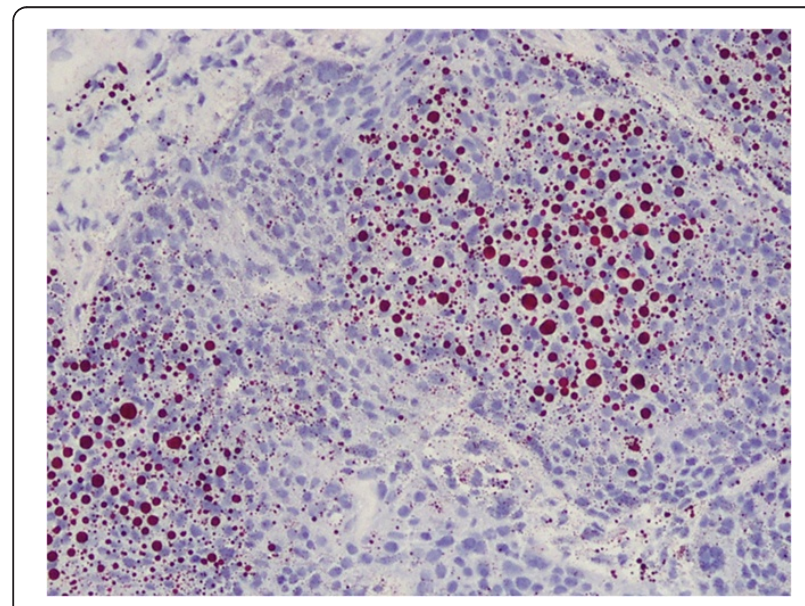

Figure 2 Accentuation of lipid by staining. The lipid globules have a red color (frozen sections, oil red $\mathrm{O}$, magnification $\times 100$ ).

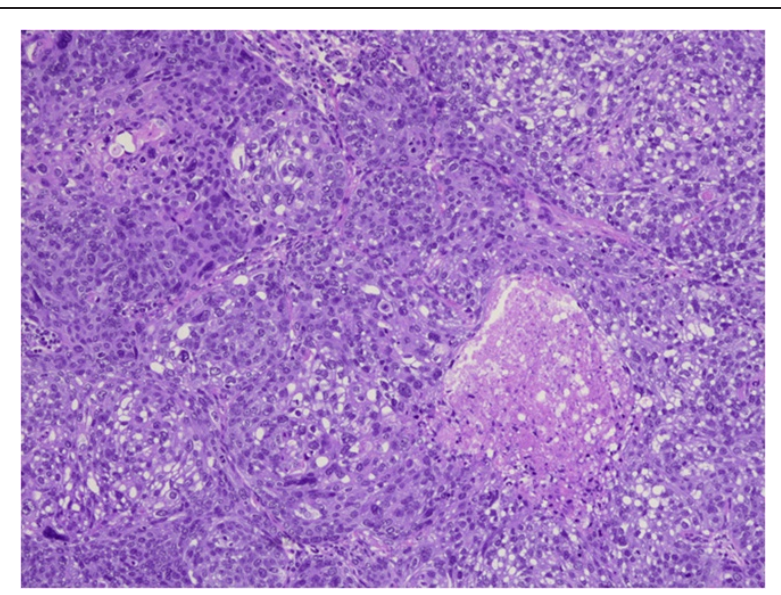

Figure 3 Sebaceous carcinoma cells. Foamy and frothy cytoplasm and atypical nuclei, occurred with numerous lipid globules within the cytoplasm of the tumors cells, seen as clear spaces (hematoxylin and eosin, magnification $\times 100$ ).

\section{Discussion}

Sebaceous carcinoma of the eyelid refers to a group of carcinomas derived from sebaceous gland cells that occur in the ocular adnexa. It can be invasive in the eyelid and conjunctiva, and can metastasize to regional lymph nodes and distant organs $[8,13,14]$. Treatment strategies for primary eyelid sebaceous carcinoma are surgery, radiotherapy, and chemotherapy [15-17]. Distant hematogenous metastases to the lung, liver, and brain have a mortality rate as high as $30 \%[16,18]$. However, few reports demonstrated the surgical treatment of metastatic eyelid sebaceous carcinoma.

Standard treatment strategy for pulmonary metastatic sebaceous carcinoma has not yet been established because of the limited number of cases. Chemotherapy regimens in existing reports are largely based on the combination regimens commonly used in the treatment of other forms of poorly differentiated carcinomas of the head and neck region $[19,20]$. Husain et al. reported combined chemotherapy of carboplatin and docetaxel for the patient who had multiple lung and lymph node metastases, which resulted in a $30 \%$ decrease in tumor size, but the efficacy of this regimen for sebaceous carcinoma has not yet been fully evaluated [21]. Radiotherapy for primary eyelid sebaceous carcinoma was described in several reports; however, there have been no reports describing radiotherapy for pulmonary metastatic eyelid sebaceous carcinoma [22,23]. Resection of pulmonary metastases in patients with sebaceous carcinoma is controversial. However, our case suggests that a surgical approach to lung metastasis of eyelid sebaceous carcinoma could prolong survival in certain subgroups of patients, namely, those with a limited number of metastatic nodules or a significant disease-free interval. 
The possibility of metastasis from eyelid sebaceous carcinoma or primary lung cancer cannot be predicted only on the basis of radiologic findings or disease-free interval. In the present case, we could successfully differentiate solitary lung metastasis of eyelid sebaceous carcinoma from primary lung cancer using oil red $\mathrm{O}$ stain, which stains lipid has a red color, on frozen sections.

\section{Conclusion}

We report a rare case of solitary lung metastasis of eyelid sebaceous carcinoma, which was successfully resected and differentiated from primary lung cancer using oil red $\mathrm{O}$ stain on frozen sections. Pulmonary resection is a good option for the treatment and diagnosis of metastatic eyelid sebaceous carcinoma.

\section{Consent}

Written informed consent was obtained from the patient for the publication of this case presentation and accompanying images. A copy of the written consent is available for the review by the Editor-in-Chief of this journal.

\section{Abbreviations}

CT: Computed tomography; FDG: Fluorodeoxyglucose; PET: Positron emission tomography.

\section{Competing interests}

The authors declare that they have no competing interests.

\section{Authors' contributions}

KK and TO wrote the manuscript. KK, TO, KA, and IK performed surgery. YH and KE carried out the pathological examination. MK and TG were involved in the final editing. All authors approved the final manuscript.

\section{Author details}

'Department of Surgery, Section of General Thoracic Surgery, Keio University, 35 Shinanomachi, Shinjuku-ku, Tokyo 160-8582, Japan. ${ }^{2}$ Department of Pathology, School of Medicine, Keio University, Tokyo, Japan.

Received: 19 February 2014 Accepted: 7 April 2014

Published: 23 April 2014

\section{References}

1. Cook BE Jr, Bartley GB, Cook BE Jr, Bartley GB: Treatment options and future prospects for the management of eyelid malignancies: an evidence-based update. Ophthalmology 2001, 108:2088-2209. quiz 2099-2100, 2121.

2. Lai TF, Huilgol SC, Selva D, James CL: Eyelid sebaceous carcinoma masquerading as in situ squamous cell carcinoma. Dermatol Surg 2004, 30:222-225

3. Leibovitch I, Selva D, Huilgol S, Davis G, Dodd T, James CL: Intraepithelial sebaceous carcinoma of the eyelid misdiagnosed as Bowen's disease. J Cutan Pathol 2006, 33:303-308.

4. Pereira PR, Odashiro AN, Rodrigues-Reyes AA, Correa ZM, de Souza Filho JP, Burnier MN Jr: Histopathological review of sebaceous carcinoma of the eyelid. J Cutan Pathol 2005, 32:496-501.

5. Sinard JH: Immunohistochemical distinction of ocular sebaceous carcinoma from basal cell and squamous cell carcinoma. Arch Ophthalmol 1999, 117:776-783.

6. Chao AN, Shields CL, Krema H, Shields JA: Outcome of patients with periocular sebaceous gland carcinoma with and without conjunctival intraepithelial invasion. Ophthalmology 2001, 108:1877-1883.

7. Shields JA, Demirci H, Marr BP, Eagle RC Jr, Shields CL: Sebaceous carcinoma of the eyelids: personal experience with 60 cases. Ophthalmology 2004, 111:2151-2157.
8. Shields JA, Demirci H, Marr BP, Eagle RC Jr, Shields CL: Sebaceous carcinoma of the ocular region: a review. Surv Ophthalmol 2005, 50:103-122.

9. Yen MT, Tse DT, Wu X, Wolfson AH: Radiation therapy for local control of eyelid sebaceous cell carcinoma: report of two cases and review of the literature. Ophthal Plast Reconstr Surg 2000, 16:211-215.

10. Wang JK, Liao SL, Jou JR, Lai PC, Kao SC, Hou PK, Chen MS: Malignant eyelid tumours in Taiwan. Eye (Lond) 2003, 17:216-220.

11. Zenda S, Kawashima M, Nishio T, Kohno R, Nihei K, Onozawa M, Arahira S, Ogino T: Proton beam therapy as a nonsurgical approach to mucosal melanoma of the head and neck: a pilot study. Int J Radiat Oncol Biol Phys 2011, 81:135-139.

12. Zenda S, Kohno R, Kawashima M, Arahira S, Nishio T, Tahara M, Hayashi R, Kishimoto S, Ogino T: Proton beam therapy for unresectable malignancies of the nasal cavity and paranasal sinuses. Int J Radiat Oncol Biol Phys 2011, 81:1473-1478.

13. Ginsberg J: Present Status of Meibomian gland carcinoma. Arch Ophthalmol 1965, 73:271-277.

14. Rao NA, Hidayat AA, McLean IW, Zimmerman LE: Sebaceous carcinomas of the ocular adnexa: a clinicopathologic study of 104 cases, with five-year follow-up data. Hum Pathol 1982, 13:113-122.

15. Gardetto A, Rainer C, Ensinger C, Baldissera I, Piza-Katzer H: Sebaceous carcinoma of the eyelid: a rarity worth considering. Br J Ophthalmo/ 2002, 86:243-244.

16. Kass LG, Hornblass A: Sebaceous carcinoma of the ocular adnexa. Surv Ophthalmol 1989, 33:477-490.

17. Lan MC, Lan MY, Lin CZ, Ho DM, Ho CY: Sebaceous carcinoma of the eyelid with neck metastasis. Otolaryngol Head Neck Surg 2007, 136:670-671.

18. Boniuk M, Zimmerman LE: Sebaceous carcinoma of the eyelid, eyebrow, caruncle, and orbit. Trans Am Acad Ophthalmol Otolaryngol 1968, 72:619-642.

19. Midena $E$, Angeli CD, Valenti M, de Belvis V, Boccato P: Treatment of conjunctival squamous cell carcinoma with topical 5-fluorouracil. $\mathrm{Br} \mathrm{J}$ Ophthalmol 2000, 84:268-272.

20. Yeatts RP, Engelbrecht NE, Curry CD, Ford JG, Walter KA: 5-Fluorouracil for the treatment of intraepithelial neoplasia of the conjunctiva and cornea. Ophthalmology 2000, 107:2190-2195.

21. Husain A, Blumenschein G, Esmaeli B: Treatment and outcomes for metastatic sebaceous cell carcinoma of the eyelid. Int J Dermatol 2008, 47:276-279.

22. Hata M, Koike I, Omura M, Maegawa J, Ogino I, Inoue T: Noninvasive and curative radiation therapy for sebaceous carcinoma of the eyelid. Int $J$ Radiat Oncol Biol Phys 2012, 82:605-611.

23. Howrey RP, Lipham WJ, Schultz WH, Buckley EG, Dutton JJ, Klintworth GK, Rosoff PM: Sebaceous gland carcinoma: a subtle second malignancy following radiation therapy in patients with bilateral retinoblastoma. Cancer 1998, 83:767-771.

doi:10.1186/1477-7819-12-108

Cite this article as: Kaseda et al.: Surgical treatment of a solitary pulmonary metastasis from eyelid sebaceous carcinoma: report of a case. World Journal of Surgical Oncology 2014 12:108.

\section{Submit your next manuscript to BioMed Central and take full advantage of:}

- Convenient online submission

- Thorough peer review

- No space constraints or color figure charges

- Immediate publication on acceptance

- Inclusion in PubMed, CAS, Scopus and Google Scholar

- Research which is freely available for redistribution 